\title{
The Outcomes of Learning a Foreign Language: Cases of Rural Primary Schools in Botswana
}

\author{
Eureka Mokibelo \\ University of Botswana, Gaborone, Botswana
}

\begin{abstract}
This paper examines the outcomes of learning a foreign language on the learners in rural primary schools of Botswana. The task is carried out through scrutinising learners' writings from English language lessons. This paper is part of a larger study that studied the implementation of Botswana language-in-education policy in ethnically and linguistically complex classrooms. The trend from literature review indicates that ethnic minority learners have a problem in coping with English as a foreign language. The study adopted the qualitative approach and used classroom observations, open-ended questionnaires, and interviews to collect data. The sampled learners' artefacts were from schools where at initial school entry, learners speak different home languages, which are not necessarily school languages. The findings of the study indicate that learners find it difficult to acquire proficiency in English as a foreign language, leading to poor performance. Poor comprehension, lack of understanding, and lack of acquisition impact negatively on the students' general academic performance. The study concludes that it is necessary to reflect on the teaching and learning methods that suit learners who speak home languages that are different from the school languages. The study recommends that teachers be trained to use pedagogical approaches suitable to handle ethnically and linguistically complex classrooms.
\end{abstract}

Keywords: foreign language, teaching methods, ethnic minorities, learners' artefacts

\section{Introduction}

Learning English as a foreign language is viewed as a problem in many countries. It appears that English acts as a barrier to transmitting knowledge and ideas in the classrooms. For example, Benson (2004) argued that the poorest and most marginalised are acutely aware that access to education through English medium is limited. Hu and Alsagoff (2010, p. 372) further argued that the use of English as an instructional language in many programmes has interfered with learning of valuable skills and knowledge. The majority of English medium programmes are burdened with intractable difficulties and incapacitating constraints ( $\mathrm{Hu}, 2007)$. Many ethnic minority pupils reach the end of compulsory schooling without attaining full proficiency in English (Deuchar, 2006). The few studies cited above indicate that English poses serious challenges in the classroom, and Botswana is not an exception.

This paper examines the outcomes of learning English as a foreign language using learners' writings and responses in both oral and written communication in English in three rural primary schools. The main reason is to examine the effect of the language-in-education policy and its implications on the learners. The policy demands that at Standard 2, the medium of instruction should be English, despite the fact that in some

Eureka Mokibelo, Ph.D. candidate, senior lecturer, Communication and Study Skills Unit, University of Botswana. 
situations, learners are still struggling with the national language that was introduced at Standard 1. Therefore, the learners struggle with the structure of the two languages and the content, which can be cumbersome for both the learners and the teachers. The paper could influence the review of the teaching of English and the pedagogy used especially in teaching ethnic minority learners. Again, the discussion provides insights into the extent to which the policy is realistic in some regions of Botswana.

\section{Language Ecology of Botswana}

Various researchers provide different numbers of languages spoken in Botswana. For instance, Nyati-Saleshando (2011), quoting Batibo (2005), said that there are 28 languages; Molosiwa (2005, p. 16) pointed out that there are more than 25 languages. The reason for such uncertainties is that research has not yet established the exact number of languages in Botswana due to the blurred distinction between a language and a dialect. Nyati-Ramahobo (2000) stated that some scholars estimated that $80 \%$ of Botswana population speak Setswana as a lingua franca while the Population and Housing Census Report 2001 (Republic of Botswana, 2001) put the figure at $78 \%$.

At independence, there was no clear language-in-education policy in schools. English dominated in the teaching and learning process while Setswana was used at lower levels of primary (Mokgwathi, 2011, p. 6). Setswana was the medium of instruction from Standard 1 up to Standard 4, while transition to English varied according to the language competence of the teacher (Molosiwa, 2005). Although English was the language of instruction after Standard 4, teachers were allowed to code-switch between Setswana and English to aid students' grasp of information (National Commission on Education (NCE), 1977). It was not uncommon to find Setswana being used as a medium of instruction in Standard 7 (Republic of Botswana, 1993). In at least one instance where Setswana was not a home language for the majority of learners, that is the North-East, the mother tongue, Ikalanga, was used in teaching and learning (Molosiwa, 2005; Mokgwathi, 2011).

The 1977 NCE, appointed by the Botswana government to conduct a review of Botswana's education system, promoted the status of Setswana and condemned the use of English from Standard 3. The commission argued that Standard 3 was too early to introduce learners to English. Further, it argued that the use of English at lower primary promoted low literacy in Setswana language which was needed for national identity and the development of national culture. The commission felt that Setswana must be given priority in the education system (Republic of Botswana, 1993). The commission further suggested that the Primary School Leaving Examinations (PSLEs) be changed to correspond with the use of Setswana at lower primary, so that the examination would be set in Setswana (Republic of Botswana, 1977). There was a change in the language-in-education policy to formalise the use of Setswana at lower primary. The commission recommended that a national test in Setswana should be administered after Standard 4 (NCE, 1977). The recommendation above was also reinforced by the exclusion of the Setswana grade from the aggregate scores qualifying the candidates for secondary school selection, suggesting that even if they scored a failing grade in Setswana they could still be admitted to secondary school. The commission was silent on the role of other languages spoken by learners. In a multilingual country, such as Botswana, this omission creates inequalities and learning barriers for non-Setswana speakers.

To match the global demands and align its education system with the Millennium Development Goals and Education for All goals, in 1993, the government set up another commission to review the entire educational system. This commission came up with a report known as the Revised National Policy on Education (RNPE), 
1993. This commission's mandate was to undertake a comprehensive review of the education system and to develop a system that would enable the country to better meet the demands of the challenges of the 21 st century (Republic of Botswana, 1994, p. 1). The commission felt that the language policy in use denied the child mastery of the main language tool needed for better achievement in primary school, academic achievement, and world of work. It was believed that their lack of fluency and competence in English was due to the late introduction of English. The RNPE 1993 report recommended that "English be used as the medium of instruction from Standard 2 as soon as practicable" (Republic of Botswana, 1994).

However, it should be pointed out that all the phases that the language-in-education policy has gone through seem neither to have improved proficiency in English nor raised the status of Setswana and use as a unifying factor. Instead, the shifts have managed to widen the gaps that exist between the major and minority language groups of Botswana (Chebanne, 2002). According to Nyati-Ramahobo (2004), the changes have inflicted some differences of opinions amongst ethnic groups with regard to the recognition of specific cultures and languages.

\section{Theoretical Framework}

This paper uses the Input Hypothesis Theory by Krashen (1985) as its theoretical framework. The input hypothesis is part of the theory of second language acquisition which has other components, such as the acquisition learning hypothesis, the natural order hypothesis, the monitor hypothesis, the affective filter hypothesis, and the reading hypothesis. The input hypothesis was advanced in 1985, and states that learners acquire language in one way only: when learners are exposed to input in written or oral form that is comprehensible to them. Learners acquire language when they are exposed to input at $i+1$, where $i$ is the current state or stage of language proficiency. Learners use their existing acquired linguistic competence together with their general knowledge of the world to make sense of the messages they receive in language just beyond where they currently are $(i+1)$. Given comprehensible input at $i+1$, acquisition will take place effortlessly and involuntarily.

Input Hypothesis Theory has implications for teachers. It means that their instruction in the classrooms should be full of rich input, both spoken and written, and that the instruction should be roughly tuned at the appropriate level for the learners in class. Also, the theory suggests that language acquisition does not require extensive use of conscious grammatical rules, and does not require tedious drills. Therefore, it is critical for learners to receive input from their teachers and classmates. Further, the theory suggests that the teacher must provide new material that builds on the learners' prior knowledge. According to Krashen (1985), the best methods are those that supply comprehensible input in low anxiety situations containing messages that students really want to hear. These methods do not force early production on second language but allow students to produce language when they are ready, recognising that improvement comes from supplying communicative and comprehensible input and not from forcing and correcting production. Furthermore, the theory suggests that teacher talk in the classroom meets the requirements of comprehensible input and perhaps the students' participation in a classroom conducive for learning. Krashen (1985) suggested that students' participation could be enhanced through small group setting that allows for more comprehensible input through interaction; more opportunity for oral practice and repetition of content; feedback and correction that are non-judgemental and immediate; and new learners negotiate meaning. Therefore, the input hypothesis demands more effort on the teacher to apply teaching and learning styles that suit the learners and provide input in various forms and shapes 
for the learners to acquire second language.

\section{Education in Botswana}

There have been a number of educational institutions that offer preschool education. Preschools are privately owned in Botswana and English is the medium of instruction in most if not all of them especially in urban and semi-urban areas. Preschool training has been inaccessible to children from poor families and rural areas, and about $90 \%$ of eligible poor children do not access preschool education. However, in Ghanzi District, through Bokamoso Trust, children in rural areas receive early education as a foundation to formal learning and other transitions in life in mother tongue. Through the Bokamoso Early Childhood Educational Programme, vulnerable children have been reached. This access to early childhood learning education for children in remote settlements, urban slums, and disadvantaged groups of people has been made possible through the training of preschool teachers (Kuru Family of Organisations, 2010). Learners are taught in their mother tongue by teachers who speak their mother tongue. However, in 2013, the Government of Botswana piloted preschool education in about 200 primary schools to prepare learners for primary education. How effective these schools are is yet to be seen because it is still a new project.

Education in primary schools of Botswana takes seven years. The government insists that all eligible children should be enrolled in primary education to access education. The number of primary schools was increased from 250 to 770 to meet this goal. This was done in line with the Millennium Development Goal No. 2 which fosters universal primary education. Botswana has achieved universal access to primary education, which provides a strong basis for the higher goal of 10 years of basic primary education. From 1995 to 2000 , the estimated net enrolment rate for children aged 7-13 was consistently above $95 \%$, peaking at $100 \%$ in 1999 and 2000 (Republic of Botswana, 2004). The medium of instruction in primary schools has always been Setswana in the initial stages of learning since 1966 to 1977, while English was used from Standard 4 from 1977 to 1994. However, currently English is used as a medium from Standard 2. This is an issue of concern for this paper that it could be started prematurely and therefore disadvantages learners.

Progression to junior secondary school level is no longer based on learners passing their PSLEs; some learners are admitted with a Grade D which is regarded as the lowest in primary school grading system. Therefore, progression from one level of study to another has improved, in 2002, 98.2\% of all Standard 7 learners progressed to junior certificate level. Junior certificate takes three years and then learners write their examinations. If they pass their junior certificate, they may proceed to senior secondary education. Some learners may choose to work if they wish, because they would have completed their universal primary education. Unfortunately, most learners in rural primary school do not reach junior certificate, because they would have dropped out of primary school level and those who managed to complete Standard 7 decide to stay home. English is partly a contributory factor (Hays, 2002).

Students who pass junior certificate are admitted to senior secondary school, which is a pre-requisite for tertiary education. The medium of instruction continues to be English except is Setswana which is taught as a compulsory subject for all citizens. At senior secondary level, learners are expected to pass English with a good grade to be admitted into tertiary especially at university. Though the stages of education are all important for all Botswana learners, some learners do not manage to complete the educational stages due to languages of instruction, especially English and Setswana. Hence, they remain missing in most aspects of Botswana society. 


\section{Literature Review}

There is consensus in the literature from various countries of the world that learning a second language is full of challenges. Washburn (2008) gave a detailed account of English language learning students in the class he was invited to. Washburn gave the students an experimental activity in Chinese to stimulate their thinking and to improve communication across language barriers. The students tried to learn to read numbers in Chinese, using Level 1 textbook for Chinese children. The task they were given was cognitively undemanding. None of the students understood much of the content. The students reported that they were confused, frustrated, feeling lost, stupid or dumb, and being overwhelmed. Some reported that they were bored or tuned out of the lesson. Some students reported that they were left out, felt out of place, excluded, and alone. Washburn (2008) reminded the students that the way they felt is the same way students who learn English as a second language or a foreign language feel. The most important thing is for the teachers to develop empathy and a willingness to try various strategies to help students in the English classroom because they feel isolated and alienated if they do not comprehend. Teachers should not expect miraculous results from learners, especially if the learners have different home languages and have limited exposure to the school languages.

Reddy (2014) argued that it is essential for a language teacher to understand the different theories involved in the process of teaching and learning to make teaching of English effective. According to Reddy (2014, p. 1), this understanding forms the basis for a teacher to select a proper approach, methods, and technique that would be useful to her/his learners. English as a foreign language cannot function as a second language. It has been uniformly imposed as a second language all over Botswana. If such occurs, learners could encounter problems and find the lessons complicated, uninspiring, unenjoyable, restrictive, and ineffective (Kasule \& McDonald, 2006). Reddy (2014) asserted that if teachers are to aim at good standards in English, it is high time that the Government of India takes a strong decision to formulate and implement appropriate policies that promote students' learning of English.

Suntharesan (2014) conducted a study on the role of mother tongue in teaching English as a second language to Tamil students in Sri Lanka. Suntharesan (2014) found out that mother tongue in English as a second language classes has been found to be productive, motivating, promoting learners' language proficiency, and enabling learners to attain the ability of using the language in real life situations for communicative purposes. Carless (2008) argued that mother tongue may serve social and cognitive functions, because students working in groups do not have to speak English all the time and the use of mother tongue relates to learner identity. Suntheresan $(2014$, p. 2) pointed out that learners feel frustrated and tend to believe that their identity is jeopardised if their mother tongue is made to degenerate. It is only through the mother tongue that advanced concepts can be interpreted.

Rabbidge and Chapell (2014) conducted a study to explore non-native English speaker teachers' classroom language use in South Korean elementary schools. Against what the policy stipulates, Korean teachers of English continue to use Korean in the English classrooms. They argued that the prohibition of Korean language to assist in the teaching of English is equivalent to banning a learner's particular identity. Rabbidge and Chapell (2014) pointed out that the knowledge brought to the classroom by the learners in the form of prior language knowledge needs to be exploited in the classroom using first language (see also Dewey, 1916). According to Rabbidge and Chapell (2014), first language knowledge complements second language knowledge (see also Cummins, 2000). 
The above studies indicate a pattern from various countries, Botswana included, that learners in linguistically and ethnically diverse classrooms need the support of teachers who have been trained to handle such complex classrooms to avoid falling behind in content. Further, the scholars emphasise the influence of first language on second language and foreign language learning - it builds a foundation; it is a source to tap knowledge from. Learners also need more interactive and explorative exposure to the languages of instruction. Lastly, the results imply that learners from linguistically and ethnically diverse societies possibly acquire information differently and may be prone to frustration in the learning environment.

\section{Methodology}

This study is qualitative, and uses multi-case technique to investigate the implementation of Botswana language-in-education policy in ethnically and linguistically complex classrooms. The idea was to examine this from the respondents' perspective. The study targeted schools with linguistically complex classrooms where learners speak home languages which are not used in school. The schools are located in different districts that are far apart as indicated in the map in Figure 1. For example, School A is in Ngamiland, School B is in Kweneng, and School C is in Kgalagadi. These regions where the schools are located are far apart and therefore the expectation from the implementation process and classrooms practices is expected to be different because of different cultures and environments.

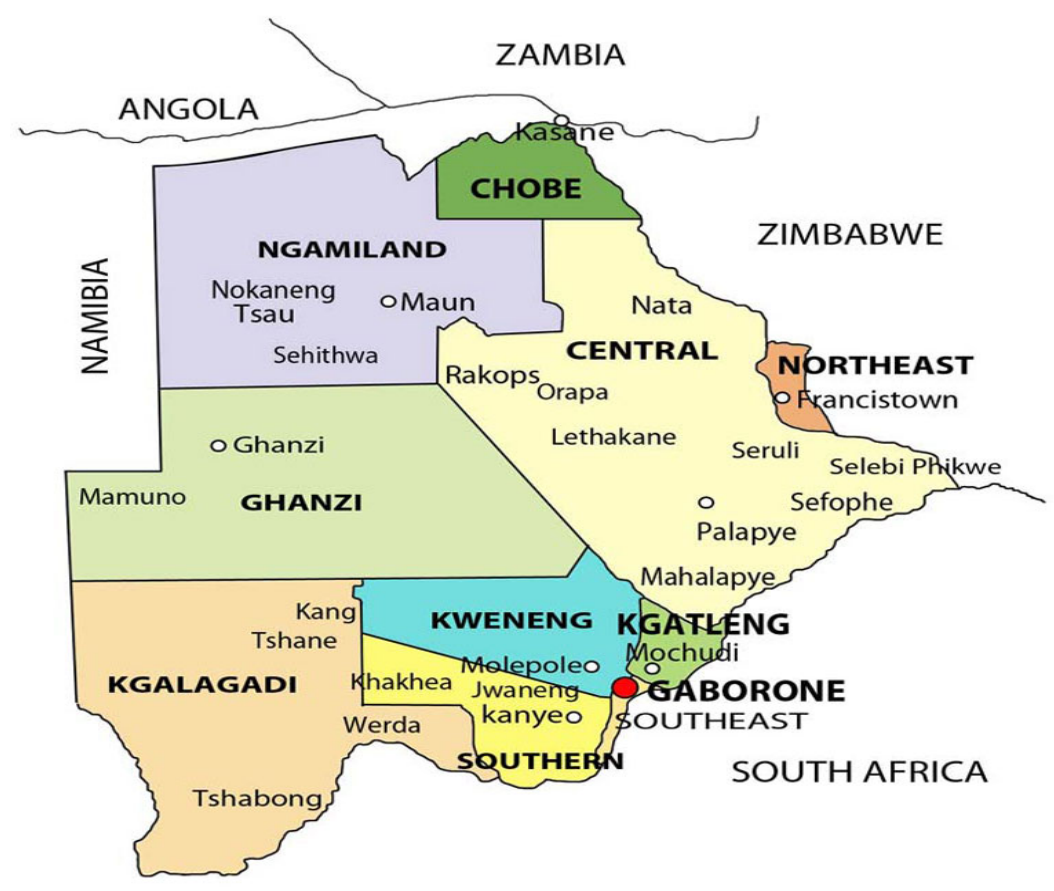

Figure 1. Botswana map showing different districts and regions.

The primary schools enrolment was characterised according to grade 2 and 3 schools. Learner enrolment for grade 2 schools was between 601 and 750 while it was between 450 and 501 for grade 3 schools. Therefore, there were two grade 2 schools and one grade 3 school. The classrooms in these schools were heterogeneous.

School A is located in a rural village with very few developments. Most of the villagers had very minimal education at primary school level or were illiterate. Most parents stayed at cattle-posts, about 10-20 kilometres 
away from the village. Some stay with their children at the cattle-post or they leave their children to stay with relatives in the village. The ethnic groups identified were Herero, San, Bakgalagadi, and a few Tswana-speaking groups. Therefore, the languages spoken in the village are Otjiherero, Shekgalagari, Setswana, and San languages, such as Ani, Buga, and Kaukau (Ju|'hoasi).

School B is also located in a rural village. The school admits learners of San origin from different rural settlements. Also, there are Bakgalagadi, Bashaga, and a small percentage of Tswana ethnic groups. The languages spoken by learners were different Shekgalagari dialects, San languages, such as Kua (\|Gana); Khute (|Gui); and Cua (Hoan), and very few Tswana speakers who speak a Setswana pigeon and Shekgalagari. The school has boarding facilities and learners do not stay with their parents most of the time. They are transported by government vehicles to and from school at the beginning and end of the school term. Most of the parents stay in rural settlements and are illiterate. They hardly ever visit schools because of poverty or lack of transport. This means that they see their children only at the end of the school term. Most of the children are frustrated by the separation from their parents and some refuse to go back to school at the beginning of the school term.

School C is located at a semi-rural village with some developments, such as tarred roads, clinics, schools, junior secondary schools, and a hospital. The villagers speak different languages, such as Afrikaans, Shekgalagari, Nama, Otjiherero, |Xoon, and Shengologa. Some parents work and others are illiterate. Most people are farmers and own livestock. Some stay in cattle-posts or cattle-ranches where they are employed as herdsman. Some parents leave their children to stay with relatives while they look after their cattle and livestock. The diversity from each school indicates that the schools are multilingual and multicultural and it is possible that English is learnt as a third or fourth language in these areas because learners are also competent in the other languages spoken in their areas.

The key participants were the teachers. In grade 3 schools, four teachers were involved, while in Grade 2 schools, eight teachers were involved. Twenty-four teachers and their classes were chosen randomly to avoid biasness. In each school, Standards 1, 2, 4, and 7 classes were examined. Standard 1 was examined because it is where the learners are introduced to Setswana (Botswana's national language). Standard 2 was examined because this is where English is introduced after learning Setswana for one year and it was interesting to see how transition from Setswana to English is done. Standard 4 was examined because the learners write attainment tests and it would be interesting to see how they cope with English such that they would use it for writing local examinations. Standard 7 was examined because this is where the learners write their final PSLEs with the medium of English and it was interesting to see whether they have acquired the basic language skills.

In all the three schools, classroom observation was done to assess teaching methods. The learners' writings were also examined. In Grade 3 schools, the researcher was supposed to examine two exercise books from each class, but due to the magnitude of the writing problems identified, four exercises were examined from each class to form an impression about the learning process. Altogether 16 exercise books from different subjects were examined in each school. In Grade 2 schools, the researcher sampled four exercise books from each class and therefore 16 exercise books were sampled. All in all, the learners' exercise book samples were 64. This helped to see the impact of English in learners' writings.

Data were collected using open-ended questionnaires, interviews, classrooms observations, and field notes. First, the open-ended questionnaires were issued. The open-ended questionnaires were important, because the teachers elaborated and explained their experiences and classroom practices in the implementation process. 
Second, the classroom observations followed after the collection of questionnaires. The classroom observations confirmed what the teachers said in the open-ended questionnaires. The classroom observations were done before and after break and the researcher observed different subjects that used English as a medium of instruction and taught English as a subject. Interviews were done after collection of open-ended questionnaires and classroom observations. Interviews were conducted in the afternoons to avoid disrupting lessons, and were done to fill in the gaps identified in the open-ended questionnaires and the classroom observations. The samples used in this paper are a representation of all the learners' writings in the three schools. Lastly, field notes were recorded at assemblies and during break time to observe the behavior of learners when they were talked to in English. The triangulation of these tools formed an impression about the learners' acquisition of a foreign language.

Data were analysed according to the key research questions to make sure that each question was answered. Answers of each key research question were grouped according to schools. The answers were further coded according to the major and minor themes under each key research question. The learners' writings confirmed and provided evidence on the major themes identified of why teachers were defying the policy and why learners were not responding positively to the policy.

The limitations of the study were that learners were not interviewed; instead their behavior in the classrooms during lessons was used to confirm their teachers' responses and their writings. However, the learners' writings and their behavior in class were insightful and made an in-depth informative conclusion about their response to English acquisition.

\section{Results: Lack of Acquisition of English (Examples From Standards 1, 2, 4, and 7 Classrooms)}

The examples used in this section are from different regions and from different primary school levels. The examples start from Standard 2 because this is where English is introduced, then Standard 4 where they write National Attainment Tests, and Standard 7 is where they write final PSLEs. It is important to follow the English language development from where it is introduced until learners write their final examinations.

\section{Example 1: Standard 2 (School A)}

The lesson was on compound words in English, and the teacher asked the learners to give examples of compound words. When there was silence, the teacher wrote some compound words on the board and asked the learners to separate the two compounded words. Still, the learners could not follow. The topic proved to be difficult for the learners to even provide examples. The teacher tried to explain in Setswana, but it was difficult for learners at Standard 2 to understand. Example 1a is the conversation that followed between the teacher and a few learners that were forced to respond.

Example 1a:

Teacher: Do you know a cattle-post?

Learner 1: Brother. (The teacher pointed at another learner.)

Learner 2: House.

From this conversation, it is not that the learners do not know what a cattle-post is, they stay in cattle-posts, but in the researcher's view, the problem was the language of instruction which they seem not to follow. For example, learner 1 gave a very strange answer to the question as well as learner 2. First, it could be interpreted 
that the learners did not understand the language and therefore this led to learners providing wrong answers. Communication breakdown can also be sensed in that the question and answers were totally different things. The learners provided nouns that were irrelevant to the question. As a way of breaking away from the frustration and pause a little bit, the teacher asked the learners to write down compound words in their exercise books. Some learners scribbled something in their books. The researcher and the teacher moved around to see what the learners have written. The researcher asked some of the learners to read what they have written because all the answers they provided were unreadable. For example, some of the answers were as follows: ise, treiddabbas, etc.. Again, learners could not read the examples they have written. The researcher's impression was that the examples provided by the learners indicated that:

1. The learners did not understand what compound words were.

2. They could not read what was written on the board as compound words or at least to imitate it.

3. When they were asked to write something, they just wrote something so that they would not be shouted at for not doing anything in class. According to the researcher's observation, some learners just opened their books and put their pen points on their exercise books but did not write anything.

4. The teacher too knew that she was talking to herself because she commented about the silence and lack of participation by saying that "the batho buang" (please, people talk), which was a way of pleading in Setswana with the learners to say something.

5. The researcher's view is that the teacher failed to simplify the topic for learners to understand.

6. Maybe the learners too were put off by the way the teacher was presenting and delivering the topic.

The teacher ended up being frustrated, because she could not achieve her goals and asked the learners to write something that she knew they did not understand and could not do the tasks.

At a corner in the same classroom, there were six learners from Herero ethnic group, who could barely write anything. They were grouped together because they were still learning some letters of alphabets from Standard 1, in particular a, b, and d. The learners wrote these letters as 6 , or they made a round shape, they could not differentiate between letter $\mathrm{b}$ and $\mathrm{d}$ at Standard 2, for example: $\mathrm{b}=6 \mathrm{P} \mathrm{p} \mathrm{6;} \mathrm{a}=600600 \mathrm{~b}$. The impression the researcher got about these six learners is that they could be in need of clinical assistance which is something beyond the language-in-education policy implementation. They seem to have learnt these letters for the whole Standard 1 period and they seem not to be getting it at Standard 2. One would be curious to see how they write at upper levels of primary and secondary school. Learning disability issues seem to be undermined in rural schools and learners lose hope along the way, hence, learners decide to drop out of school. For example, the school head in school A reported a drop out rate of 15-25 learners annually. The next example is on verbs to further demonstrate the learners' language related problems.

\section{Example 2: Standard 4 (School C)}

Examples $2 \mathrm{a}, 2 \mathrm{~b}, 2 \mathrm{c}$, and $2 \mathrm{~d}$ further demonstrate the language-related problems learners encounter in English. In this case, the teacher had given learners verbs with which to construct sentences. From the students writings, it is difficult to tell which verbs were provided because the spellings are wrong.

Example 2a (Girl child):

Thise animals whotbeatosees

Harkes d mane ahlaigt w 
Tradito nag rhaetha

Albonimgiswereng

Example 2b (Boy child):

Bmebsono mots boll semeon

Memsisetthmebmsegmoss

Tsomomeotsoseotsets

Example 2c (Boy child):

My senisea is iseaiso

The gira is omens!

My name is anmoseoses

Example 2d (Girl child):

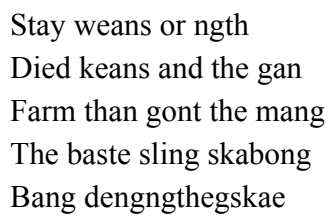

The learners were responding to the same task of filling in the verbs.

In light of the above examples, it is difficult to interpret what could be the learners' problems. But the researcher's impression is that the learners cannot copy words or phrases from the board, because the learners were given single words with sentences written on the board to fill in the blanks and they failed to fill in the correct verb. Again, the researcher did not see the instruction and the verbs provided and it is difficult to find out from the learners answers which verbs were used. The learners could have at least copied the sentences correctly and filled in the words with correct spellings because they were already provided, but it did not happen. Maybe the learners did not understand the instruction in English, because they jumbled up the sentences and wrote whatever came to their mind, one would not tell from the examples that they were given the same task. It would be reasonable to consider them failures of the National Attainment Tests at Standard 4 level if they could still be writing as such by the end of the year 2012, given that they were left with about seven months to write their National Attainment Tests.

\section{Example 3: Standard 7 (School A)}

In Example 3a, the learners were supposed to match the word with the correct meaning and below is what one learner wrote.

Example 3a (Meaning of words):

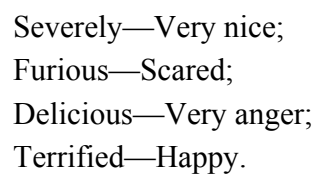

The learner failed to match the correct meaning with the words. This showed that the learners did not understand the words.

In Example 3b, the learners were given jumbled up sentences to write them correctly. However, it was 
not clear how the jumbled up sentences were presented initially to determine how poorly they were performed.

Example 3b (Sentence construction):

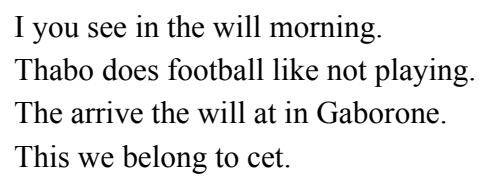

Examples $3 \mathrm{a}$ and $3 \mathrm{~b}$ at Standard 7 are an indication that the learners did not understand the meaning of individual words and had no idea on how to put them together to construct meaningful sentences. Again, it could have been that the sentences were presented as the learners had written them and did not know how to rearrange the words in different sentences. Further, some spellings are wrong and it is unlikely that the teacher could have provided the wrong spellings.

\section{Example 4: Standard 7 (School B)}

The following sentence constructions (see Example 4a) were observed in the students' exercise books. It was not clear what the instruction was, but it looks like the learners were supposed to construct correct sentences after being given jumbled up sentences.

Example 4a:

The man it voice rope the zebras was.

The mrnodisa was owns the by the store in the village.

The paid thief will cope catch big guy.

From Example 4a, the learner knows different words, but has no idea how he has to put them in order to construct correct sentences. Words were just thrown in the sentence haphazardly and this results in sentences not making sense. It is important to note that the learner was left with five months to write PSLEs of 2012. How this learner is going to perform leaves much to be desired, because it looks like he is not coping with the language of instruction, English. The teacher confirmed that most learners write as such in her classroom.

In Example 4b, the learners were supposed to write a composition and the researcher copied what a learner wrote in his exercise book.

Example 4b:

It is look if you go at cattlepost you going to see butiful but it is no playground we playing in home at cattlepost, most people we no at. Gaborone hw or has he have a electricity and at cattlepost we do not have a electricity afethir a week my herd grenfathr he going at...

Example $4 \mathrm{~b}$ also reveals that indeed English presents problems, notably spellings, tenses, grammatically incorrect sentences, and the paragraph does not make sense. The example shows that some learners neither comprehended nor understood English even after spending almost six years in school.

The examples used above are not exhaustive. The results of the study indicate that learning English as a foreign language presents challenges that are a consequence of many factors, such as the input provided that does not reach the students in rural areas, overlooking the linguistic and cultural diversity in the classrooms, the lack of transfer of traits from the learners' mother tongues to English, another language interferes-Setswana (the national language), and inappropriate teaching pedagogy. 


\section{Discussion of Findings}

\section{Early Exit to English Is Problematic in Rural Primary Schools}

The examples from learners' exercise books from different schools of different regions are an indication that learners have a problem in acquiring basic language skills in English from Standard 2. The few examples provided indicate that learners have problems in learning English which could be caused by many factors. One of the reasons could be early exit to English at Standard 2, because learners struggle with a newly introduced language at Standard 1 and then before they could acquire basic language skills in Setswana within the one-year school calendar, a foreign language is introduced. In light of examples provided in the three schools, English disempowers the learners, because it limits their expression in writing, reading, and speaking as observed in the classrooms and learners' writings. Scholars, such as Bamgbose (1997), Hays (2002), Lam (2002), Le Roux (1999), May (2004), and Prah (2009) argued that learners from ethnic minority groups are unable to express themselves in the target language especially English. The results of the overall performance in various subjects where English is used as a medium indicate that learners do not comprehend English and consequently, they are not able to use it in various communication situations. This leads to disastrous outcomes of the policy intentions.

\section{Lack of Transfer of First Language Traits to English}

Botswana education system follows the bilingual education model where learning has to start with the learners' first language. In this study, learners are not starting to learn in their first language, in fact, the national language could be their second, third, or fourth language. The difference with learners in this study is that they come to school speaking their home languages, they have to transit from their home languages to Setswana and then to English. They have to go through this transition three times with very minimal assistance. It looks like the issue of lack of transfer is overlooked by teachers. The expectation is that learners will transfer first language skills to English. In this study, learners are not transferring any first language skills to English. Therefore, the difficulty of learning English could be complicated by the gap between their language and Setswana that is taught and used as a medium in less than one year of the school calendar. If these learners were using their first language at early learning, maybe the situation could be different when they learn English. Butzkamm (2003) once remarked on the use of mother tongue at early learning that:

Mother tongue opens the door, not only to its own grammar, but to all grammar in as much as it awakens the potential for universal grammar that lies within all of us. The mother tongue is the key to foreign languages, the tool which gives us the fastest, surest, most precise, and most complete means of accessing a foreign language. (p. 3)

Since learners in rural primary schools do not transfer any traits from their mother tongues, it could be one of the contributory factors of such learners' writings.

\section{Pedagogy Used for Teaching and Learning English as a Foreign Language}

The examples sighted in the results section do not indicate any rigorous and robust pedagogy in learning English to bring about the desired change. There is an indication that most of the instruction followed was the lecture method and giving learners exercises that were not clearly understood. During classroom observations and information gathered from open-ended questionnaires, common pedagogy across the schools, such as repetition of answers by whole class, singing answers in chorus, and drilling to teach English was observed. For example, here are some of the repetitions observed in the Standard 2 classrooms that indicate that not all is well 
in the English lessons. This exercise was oral and practical. Learners had to sing and do as they say.

“... Clap your hands, stamp your feet, jump up and down, sit on your feet, wiggle your toes and bend your knees..." (Source: Standard 2 class, School A).

In this exercise, when learners were asked to clap their hands, they would sit down while some walked or remain standing; when they were asked to stamp their feet, some would touch their head or run; when they were asked to sit down, they clapped their hands or stamped their feet. In brief, the whole exercise was chaotic even though the learners were in the second term of doing the exercise. There was an indication that they did not totally understand English instruction.

A similar example to justify that the repetition and singing of answers in chorus were ineffective during an English lesson is used below.

The learners were supposed to sing in chorus and act out the recitation after the teacher:

“... Frogs hop, cats leap, dogs run, bugs creep, worms squirm and birds fly ...” (Source: Standard 2 class, School C).

Also in such an exercise, when some learners are supposed to hop, they fly or run; when they are supposed to creep, some hop or leap; when they were supposed to squirm, some leap or fly. In actual fact, the learners would even knock against each other in the small space provided for doing the exercise because of acting out differently for the same instruction.

When asked about the method that seems to be ineffective for learners, one of the research participant teachers said, "This strategy works for me, it keeps the learners busy and at least they cram something from singing the answers". This response could mean that it is okay for learners to sing the answers even if they do not understand what they are saying. Cramming does not show understanding and comprehension of what is being said. In one of the schools, one of the research participant teachers justified why they used the repetition and singing of answers. The reasons advanced were that it kept the classrooms noisy. However, the researcher observed that:

1. Teachers allowed learners to sing the answers in chorus without understanding. When they were asked a question, they were able to answer in a group; individually some of the learners were unable to do so.

2. Teachers used the repetition method with the belief that the answers will stick in the learners' minds.

3. The repetition and drilling will help the learners pronounce the English words correctly.

4. Noise in the classrooms is an indication that teaching and learning is taking place, or at least the learners are not playing. Teachers who supported this method did not elaborate on how this method developed the learners' basic language skills in English.

If all the teaching methods used by teachers to learn English as a foreign language were effective, it would improve the results of the learners in Standard 4 where they write National Attainment Tests and Standard 7 where the learners write their PSLEs with the English medium. But the pedagogy used by teachers at Standard 2 to 7 levels proved to be ineffective, because learners were unable to comprehend and understand English. There was evidence that lack of support services, such as teacher preparation and pedagogical practices, uneven quality control, and inadequate communication, limited learners' educational outcomes and opportunities (Cumming-Potvin, Renshaw, \& Kraayenoord, 2003). One would expect such mechanisms to be provided especially if the learning of English presents challenges as in linguistically complex classrooms. However, academically, repetition, singing answers in chorus, and drilling may not be appropriate ways of teaching and learning a foreign language. Learners may not learn and it does not help the learners work independently or 
become autonomous. This could be the reason why teachers in Standard 4 and subsequent levels complain about learners who cannot comprehend and understand concepts in English. To highlight some of the problems of learning a language, Kaplan, Baldauf, and Kamwangamalu (2011) argued that the reason why some language-in-education policies fail is because the methodology used may not be appropriate to produce the desired outcomes. Considering that the learners come from different regions and backgrounds, they may not respond the same way to the same pedagogy. Further, if the learners are taught with the same methodologies, it leaves doubts on whether teachers have been empowered to teach such complex classrooms, the "one size fits all" pedagogy may not be the solution to the acquisition of English. The learners in rural primary schools resisted such pedagogy in different ways, hence, the consistent poor academic results.

\section{The Input Hypothesis Theory and the Teaching of English}

The Input Hypothesis Theory which has been used as a bedrock for this paper indicates that it challenges the teachers to provide rich input in the English lessons. This was lacking because although the learners were second language or third language learners of English, there were no special programmes for English in place to address the learners' needs in English language learning. Again, the pedagogy the teachers were using was basically the same in all schools and it seems not to be making any difference regarding the teaching of English, because the results from the classrooms and the final examinations were dismally poor. Hence, it is not clear from the study how much input was provided from school management and Ministry of Education and Skills Development to foster the teaching and learning of English as a foreign language. Again, the theory requires that new material should build on learners' prior knowledge and this requires creativity and innovativeness on the part of teachers and school management. As it was indicated, teachers and learners do not have the same historical background, which made it difficult for learners and teachers to share experiences and ideas in the English lessons. This was further complicated by the fact that learners do not start learning in their first language; hence, the learning of English becomes too alien because there is no transfer of traits and knowledge from home. Learners lacked the vocabulary to express themselves in the target language making it difficult to understand and comprehend the concepts. In this regard, the teachers' pedagogy and practices fall short of the theory because the practices ran parallel with the principles advocated by the theory.

Input maybe further complicated by the training of teachers, which does not match the realities in the teaching of languages in primary schools. For example, in the past, the Ministry of Education used the generalist approach to train primary school teachers, because they were expected to teach all subjects once they get to the field (Brandon, Moorad, Bogopa, \& Dambe, 1998). However, this was challenged by the public and the teachers themselves regarding the quality of education (Mokotedi, 2013). Teacher training was then focused to offer subject specialization where teachers specialized in two subjects during training for diploma in primary education, but when they get to the field, there is no policy to support their training, hence they are expected to teach all subjects (Sharpe, 2001). This is an obvious mismatch of training and practice. Such a mismatch has implications on teacher delivery services since they may not have trained in language subjects and therefore not in a position to approach the teaching of English or languages with suitable, relevant, and applicable methods. Theory $v s$. practice can also devalue their teaching profession because they are teaching subjects that they have not trained for and therefore could make them obvious failures. Therefore, it may be difficult to provide the necessary input in the English classrooms because teachers lack language teaching skills from their training. 


\section{Implications of the Outcomes of Learning English as a Foreign Language}

Regarding the learners' writings, there are implications of such kind of writing affecting learners in the acquisition and learning of English as a foreign language. The implications are that: Firstly, learners are not effectively learning, and therefore, not acquiring English language skills, because even at completion level, learners are unable to write constructively. Secondly, through English, the education system kicks out learners early, because they find no reason to sit in the classrooms without benefitting and therefore decide to desert school. In the three schools studied, around 25 learners dropped out of school annually especially between Standards 1 and 2 and the learners did not advance reasons for disengaging from school. However, the suspicion is that English could be one of the contributory factors. Thirdly, the language-in-education policy discriminates against the learners in rural primary schools, because Botswana is a multilingual country and the fact that the language-in-education policy recognises English as a medium from Standard 2 and subsequent levels; the policy automatically leaves out learners who learn it as a foreign language. Further, these learners would not contribute towards the political, economical, and academic development of their country, because lack of understanding and acquiring English language skills, instead English contributes towards their disengagement from school. Lastly, the learners do not develop and grow into citizens who can sustain themselves and will ever be dependent on the government and in this regard, the government would have failed to sustain their human development.

Learners in rural primary schools studied are not accessing basic education due to lack of acquisition of English. In order to meet the above United Nations Educational, Scientific, and Cultural Organization (UNESCO) goal, Botswana increased its enrolment at primary school level. From 1995-2000, the estimated net enrolment rate for children aged 1-13 was consistently above $95 \%$ and peaking at 100\% in 1999-2000. Looking at the learners' artefacts in English lessons and the pass rate in final examinations, it may be logical to conclude that for Botswana government, access to primary education meant increasing the number of learners in the classrooms and building more schools to accommodate more learners. The government did not consider that while these children sit in the four walls of the classrooms, they should also acquire knowledge and skills. They should not leave the classrooms with very little education because of English. It is evident from the learners' artefacts that they are not benefitting from the English lessons. This is also supported by the PSLE results which are consistently low in the schools studied. Further, the Universal Declaration of Human Rights, Article 26(1), states that "Everyone has a right to education" (United Nations, 1948). English as a foreign language makes it difficult for the learners in this study to access their right. Going to school every day to increase the number of learners' attendance does not help learners access their right. This situation calls for rigorous reflection of the policy itself, on the teacher pedagogy as well as the input provided to enhance learning.

\section{Conclusion}

Indeed the outcomes of learning English as a foreign language are disastrous in the three primary schools. The analysis from learners' writings, classroom observations, and teacher interviews provides empirical evidence that learners seem not to acquire English from Standard 2 and subsequent levels where it is used as a medium of instruction. Using teacher pedagogy, such as the repetition, drilling, and chorus answers to teach a language that learners do not understand creates problems. For this reason, it can be concluded that learning of English is not universal; it should be contextualised to cultural specificity to help the language classroom to 
serve as a bridge between home and school. Evidence from the study indicates that the linguistic and cultural diversity of the learners is not preserved; the teaching methods do not affirm and protect such diversity to enhance the learning of English. It is not that learners are incapable of learning English as a foreign language, but learners' language and indigenous knowledge are not utilized. Instead, the policy assimilates learners such that they sacrifice their linguistic and cultural heritage.

As key implementers of English, teachers should have a clear understanding of what they are expected to do. Currently, their training does not match the realities in primary schools. They are expected to deliver in all subjects and yet their training confines them to specialize in two subjects only. The mismatch is an obvious barrier on the outcomes of teaching and learning of English. The teaching methods practiced have to bring about change and it is important to understand how teachers facilitate this change. Teachers in this study seem not to be able to handle complex classrooms. Further, foreign language learning depends on the intensity, duration, and quality of foreign language instruction. These have to be taken into account to make a difference. If the input is on learning English is too minimal, it may not make much difference. The teaching and learning pedagogies used in such classrooms to learn English do not suit the complexity in the classrooms in terms of learners' cultural background and culture. The expectation is that qualified teachers should be able to analyse any culture bump in the classroom and apply it to their own experiences before applying it to the learners (Thorp, 1991). The current language-in-education policy may not enable both teachers and learners to achieve educational goals as regards the teaching and learning of English. The teaching pedagogy and teachers' proficiency in English also influences the learners' writings and acquisition of English.

\section{References}

Arthur, J. I. (1995). Policy, practice and pedagogies: A case study of languages in Botswana. Journal for Language Teaching, $33(1), 60-71$.

Baker, C. (1993). Foundation of bilingual education and bilingualism. Clevedon, U.K.: Multilingual Matters.

Bamgbose, A. (1997). Language and the nation: The language question in sub-Saharan Africa. Edinburgh, U.K.: Edinburgh University Press.

Batibo, H., \& Smieja, B. (2005, February 11). Minority speakers' attitude towards their languages: Causes, implications and reversal strategies. Paper presented at The UBTROMSO San Collaborative Research Seminar, University of Botswana.

Benson, C. (2004). Do we expect too much of bilingual teachers? Bilingual teaching in developing countries. Bilingual Education and Bilingualism, 7(2\&3), 204-221.

Brandon, D. B., Moorad, F. R., Bogopa, G. G., \& Dambe, M. R. (1998). A survey of prospective teachers' perceptions of the usefulness of teacher training programmes in Botswana. Mosenodi, 6(2), 45-52.

Butzkamm, W. (2003). We only learn language once. The role of mother tongue in foreign language classrooms: Deaths of a dogma. Language Learning Journal, Winter(28), 29-39.

Carless, D. (2008). Student use of mother tongue in the task based classroom. ELT Journal, 72(4), 331-338.

Chan, W. H., \& Nicoladis, E. (2010). Predicting two mandarin English bilingual's first 50 words: Effects of frequency and relative exposure in the input. International Journal of Bilingualism, 14, 1-34.

Chebanne, A. (2002). Minority languages and minority people: Issues on linguistic, cultural and ethnic death in Botswana. In I. Mazonde (Ed.), Minorities in the millennium: Perspectives from Botswana (pp. 47-56). Gaborone: Lightbooks.

Chomsky, N. (1972). Selected readings. London, U.K.: Oxford University Press.

Crystal, D. (1972). The case of linguistics: A prognosis. British Journal of Disorders of Communication, 7, 3-16.

Cumming-Potvin, W., Renshaw, P., \& Kraayenoord, C. (2003). A socio-cultural analysis of language learning: New forms of literacy practices in a language and culture awareness programme. Language and Education, 17(6), 391-405.

Cummins, J. (2000). Language, power, and pedagogy: Bilingual children in the crossfire. Clevedon, U.K.: Multilingual Matters.

Deuchar, M. (2006). Welsh-English code-switching and the matrix language frame model. Lingua, 116(11), 1986-2011. 
Dewey, J. (1916). Democracy and education: An introduction to the philosophy of education. New York, N.Y.: Free Press. Retrieved from http://www.ilt.columbia.edu/publications/dewey.html

Hays, J. (2002). Education and the San of Southern Africa: The search for alternatives. In I. Mazonde (Ed.), Minorities in the millennium: Perspectives from Botswana (pp. 73-88). Gaborone: Lightbooks.

Hu, G., \& Alsagoff, L. (2010). A public policy perspective on English medium instruction in China. Journal of Multilingual and Multicultural Development, 31(4), 365-382.

Hu, Y. (2007). China's foreign language policy on primary education. What's behind it? Language Policy, 6, 359-376.

Johnson, D. C. (2010). Implementation and ideological spaces in bilingual education language policy. International Journal of Bilingual Education and Bilingualism, 13(1), 61-69.

Kaplan, R. B., Baldauf, R. B., \& Kamwangamalu, N. (2011). Why education language plans sometimes fail. Current Issues in Language Planning, 12(2), 105-124.

Kasule, D., \& McDonald, R. (2006). Teacher practices and verbal interaction in primary school classrooms in Botswana. Language Matters, 37(1), 16-43.

Krashen, S. (1985). The input hypothesis: Issues and implications. New York, N.Y.: Longman.

Kuru Family of Organisations. (2010). Annual report 2010. Ghanzi: Kuru Family of Organisations.

Lam, A. (2002). English in education in China: Policy changes and learners' experiences. World Englishes, 21(2), 245-256.

Le Roux, W. (1999). Torn apart: San children as change agents in a process of acculturation (A report on the educational situation of San children in Southern Africa). Shakawe: Kuru Development Trust.

May, S. (2004). Maori-medium education in Aotearoa/New Zealand. In J. Tollefson, \& A. Tsui (Eds.), Medium of instruction policies: Which agenda? Whose agenda? Mahwah, N.J.: Lawrence Erlbaum Associates Publishers.

Mokgwathi, T. (2011). The role of code-switching in teaching and learning selected senior secondary schools in Botswana (Unpublished Ph.D. dissertation, University of Pretoria).

Mokotedi, R. (2013). Beginning primary school teachers' perspectives on the role of subject specialisation in Botswana colleges of education: Implications for the professional development of those who did not specialise in languages (English and Setswana). International Journal of Scientific Research in Education (IJSRE), 6(1), 88-89.

Molosiwa, A. (2005). Extinction or distinction? Empowering Setswana as the medium of instruction and instrument in Botswana schools. In B. Brock-Utne, \& R. K. Hopson (Eds.), Languages of instruction for African emancipation: Focus on postcolonial contexts and considerations. Cape Town: The Centre for Advanced Studies of African Society (CASAS).

National Commission of Education (NCE). (1977). Education for Kagisano. Gaborone: Government Printers.

Nyati-Ramahobo, L. (2000). The language situation in Botswana. Current Issues in Language Planning, 1(2), 243-300.

Nyati-Ramahobo, L. (2004). Language situation in Botswana. In R. B. Baldauf, \& B. K. Robert (Eds.), Language planning and policy in Africa Vol. 1: Botswana, Malawi, Mozambique and South Africa (pp. 21-78). London, U.K.: Cromwell Press Ltd..

Nyati-Ramahobo, L., \& Orr, R. (1993). Primary education and language teaching in Botswana. In K. Samsay, \& D. McKean (Eds.), Common threads of practice: Teaching English to children around the world (pp. 72-76). Alexandria, V.A.: Teachers of English to Speakers of Other Languages.

Nyati-Saleshando, L. (2011). An advocacy project for multicultural education: The case of the Shiyeyi language in Botswana. Springer Science + Business Media: Int Rev Educ, 57, 567-582. doi:10.1007/s11159-011-9254-4

Obondo-Okoyo, T., \& Sabone, I. (1986). Twenty years of progress: An official handbook. Gaborone: Department of Information and Broadcasting.

Ortiz, A. A., Wilkinson, C. Y., Robertson-Courtney, P., \& Kushner, M. (2006). Considerations in implementing intervention assistance team to support English language learners. Remedial and Special Education, 27(1), 53-63.

Prah, K. (2009). Mother tongue education in Botswana, literacy and multilingualism in Africa. In G. Kamwendo, D. Jankie, \& A. Chebanne (Eds.), Multilingualism in education and communities in Southern Africa (pp. 31-43). UBTromso Collaborative Programme for San Research and Capacity Building.

Rabbidge, M., \& Chapell, P. (2014). Exploring non-native English speaker teachers' classroom language use in South Korean elementary schools. The Electronic Journal for English as a Second Language, 17(4), 1-18.

Reddy, P. S. (2014). Problems in teaching/learning English as a second language in India. Language in India, 12(2), 1-6.

Republic of Botswana. (1977). Education for Kagisano: Report of the National Commission on Education. Gaborone: Government Printers.

Republic of Botswana. (1993). Report on the Revised National Policy on Education. Gaborone: Government Printers.

Republic of Botswana. (1994). Revised national policy on education. Gaborone: Government Printers. 
Republic of Botswana. (1997). Long term vision for Botswana: Towards prosperity for all. Gaborone: Government Printers. Republic of Botswana. (2001). Population and housing census report 2001. Gaborone: Government Printers.

Republic of Botswana. (2004). Millennium development goals status report. Gaborone: Government Printers.

Republic of Botswana. (2011). Analytical report: Population and housing census. Gaborone: Government Printers.

Sharpe, K. (2001). Modern foreign languages in the primary schools. London, U.K.: Kogan Page.

Suntharesan, V. (2014). The role of mother tongue in teaching English as a second language to Tamil students (Special reference to undergraduate of the University of Jaffina, Sri Lanka). EBSCO Host, 12(12), 1-6.

Sure, K., \& Ogechi, N. O. (2009). Linguistic human rights and language policy in the Kenyan education system. Addis Ababa: Organization for Social Science Research in Eastern and Southern African.

Thorp, D. (1991). Confused encounters: Differing expectations in the EAP classroom. ELT Journal, 45(2), 108-118.

United Nations. (1948). Universal declaration of human rights. Retrieved from http://www.un.org/Overview/rights.html\#a26

Washburn, G. N. (2008). Alone, confused, and frustrated: Developing empathy and strategies for working with English language learners. Heldref Publications, 8(6), 247-250. 